\title{
Medición de Cambios Cuantitativos de la Microbiota Subgingival Posterior a la Remoción de Placa Bacteriana Supragingival
}

\author{
Measurement of Quantitative Changes of the Microbiota Subgingival After to \\ Removal of Bacterial Plaque Supragingival
}

\author{
Godoy $\mathrm{C}^{1}$, Melej $\mathrm{C}^{2}$, Silva $\mathrm{N}^{1}$
}

\begin{abstract}
RESUMEN
Uno de los campos de interés en el estudio de la microbiología periodontal para muchos investigadores ha sido identificar si es posible que los microorganismos responsables del origen y progresión de la enfermedad periodontal que habitan sobre el margen gingival (supragingival) y bajo este (subgingival) tengan una relación directa que permita mantener interacciones influyentes en el crecimiento y desarrollo de las diferentes especies bacterianas que habitan en los tejidos periodontales. Por lo tanto, al remover los microorganismos que se ubican supragingivalmente sería posible encontrar cambios en el medio subgingival al no existir un intercambio entre los ambientes aerobios (supragingival) y anaerobios (subgingival) una vez desorganizada la placa bacteriana supragingival.

Para demostrar esta relación se seleccionaron 7 individuos con diagnóstico de periodontitis crónica moderada y severa a los cuales se les realizó un destartraje supragingival de boca completa para lograr desorganizar la placa bacteriana supragingival. A su vez se tomaron muestras microbiológicas de los sacos periodontales más profundos de cada cuadrante de estos individuos, siendo la primera muestra tomada previo al destartraje supragingival considerada como muestra basal (día 0), luego se tomaron a las 24 horas, a los 7 y 21 días de removida la placa bacteriana supragingival.

De los resultados del presente estudio pudimos concluir que al desorganizar el biofilm supragingival se observa una disminución en la cantidad total de microorganismos subgingivales, así como también disminuye de manera considerable la proporción de Porphyoromona gingivalis presente en el medio subgingival. Lo cual permitiría establecer la existencia de una relación directa y dependiente entre los microorganismos que habitan el medio supragingival y subgingival.
\end{abstract}

Rev. Clin. Periodoncia Implantol. Rehábil. Oral Vol. 3(1); 5-10, 2010.

Palabras clave: Muestras microbiológicas, unidades formadoras de colonia (UFC), placa bacteriana supragingival, Porphyoromona gingivalis (Pg).

\section{ABSTRACT}

One of the fields of interest in the study of the microbiology periodontal for many investigators has been to identify if it is possible that the microorganisms responsible for the origin and progression of the disease periodontal that live on the margin gingival (supragingival) and under this (subgingival) they have a direct relation that allows to support influential interactions in the growth and development of the different bacterial species that they live in the tissue periodontal. Therefore having removed the microorganisms that are located supragingivalmente would be possible to find changes in the way subgingival when an exchange not to exist between the aerobic environments (supragingival) and anaerobic (subgingival) once disorganized the bacterial plate supragingival.

To demonstrate this relation 7 individuals selected with diagnosis of periodontitis chronicle moderate and severe to which they there was realized a destartraje supragingival of complete mouth to achieve supragingival to disorganize the bacterial plate. In turn microbiological samples of the sacks took periodontales deeper of every quadrant of these individuals, being the first taken sample before the destartraje supragingival considered as sample basal (the 0 th), then they took at to 1,7 and 21 days of removed the bacterial plate supragingival anaerobios (subgingival) once disorganized the bacterial plate supragingival

Of the results of the present study we could conclude that on having disorganized the biofilm supragingival a decrease is observed in the total quantity of microorganisms subgingivales, as well as also it diminishes in a considerable way the proportion of present Porphyoromona gingivalis in the way subgingival. Which would lead to thinking that there exists a direct and dependent relation between the microorganisms that live the way supragingival and subgingival.

Rev. Clin. Periodoncia Implantol. Rehábil. Oral Vol. 3(1); 5-10, 2010.

Key words: Microbiological samples, forming Units of colony (UFC), bacterial plate supragingival, Porphyoromona gingivalis (Pg).

\section{INTRODUCCIÓN}

A finales del siglo XIX fueron descubiertos muchos microorganismos patógenos que representaban un riesgo vital para el ser humano. En la actualidad gracias a los conocimientos adquiridos sobre la forma de tratar a estos agentes patógenos ha sido posible salvar muchas vidas ${ }^{(1)}$.

Johnson TC y cols (1997) mencionan en su estudio de gingivitis experimental en individuos periodontalmente susceptibles que es imposible comprender completamente la salud y la enfermedad bucal sin identificar y entender el potencial patogénico de todas las bacterias que colonizan la cavidad bucal. Lo cual ha sido posible mediante estudios de cultivos microbiológicos y moleculares, en donde se han podido identificar más de 700 especies en el interior de la cavidad bucal humana. De estas especies más de 400 han sido encontradas en el saco periodontal, mientras que las 300 especies restantes han sido identificadas en otras zonas bucales tales como lengua, membranas de las mucosas bucales, lesiones de caries e infecciones endodónticas ${ }^{(2)}$.

La enfermedad periodontal se origina por microorganismos que residen en el margen gingival o debajo de éste. Esta aseveración nos permite pensar que el mejor método para tratar esta enfermedad podría ser controlando las especies patógenas que residen en estas ubicaciones ${ }^{(3)}$

En la cavidad oral los depósitos bacterianos han sido denominados placa dental o placa bacteriana. Estudio clínicos como e de Dahlén G y cols (1992), han demostrado de manera convincente que

1. Universidad de Chile. Chile.

2. Universidad de Antofagasta. Chile.

Correspondencia autor: Claudia Godoy. claudia.godoy.g@gmail.com Trabajo recibido el 15/12/2009. Aprobado para su publicación el 17/04/2010. 
la eliminación mecánica diaria de esta placa bacteriana en la mayoría de los pacientes podría interferir en el curso normal de la enfermedad periodontal(4).

Por otra parte la placa bacteriana podemos dividirla según su ubicación en una placa bacteriana supragingival y subgingival, lo que nos permite formular la hipótesis que sí existe una disminución en la cantidad de la microbiota total cultivable y de Porphyromona gingivalis en los sacos periodontales de pacientes con periodontitis crónica al remover la placa bacteriana supragingival.

Dentro de la biopelícula que origina la enfermedad periodontal encontramos bacterias que tienen gran protagonismo en el inicio y progresión de la enfermedad. Tal es el caso de Porphyromonas gingivalis $(P g)$, la cual corresponde a una bacteria anaerobia que reside en el surco gingival, encontrándose muchas veces asociada a formas graves de periodontitis. Este microorganismo tiene la capacidad de proliferar dentro de la biopelícula subgingival (placa bacteriana) y diseminarse desde ella, siendo esta la pieza clave de su virulencia(5).

Dentro de los objetivos que sustentan esta investigación están el identificar y comparar la cantidad de unidades formadoras de colonia (UFC) de la microbiota total cultivable presente antes de la eliminación de la placa bacteriana supragingival con respecto a las mediciones realizadas el día 1, a los 7 y 21 días de eliminada la placa bacteriana supragingival por parte del operador. De igual forma se identificó la presencia de $P g$ y se compararon los porcentajes de este microorganismo presente en las diferentes mediciones.

Los tiempos seleccionados para realizar las mediciones posteriores al destartraje supragingival fueron analizados dentro de la perspectiva histopatológica de los tejidos periodontales y de los mecanismos microbiológicos que afectan a estos tejidos. Lo cual se puede resumir en que a las 24 horas (día 1) ya existe una reorganización de un biofilms supragingival inmaduro(6), a los 7 días de acumulación de placa, se desarrolla un infiltrado inflamatorio de leucocitos mononucleares en el lugar de la lesión inicial(4) y a los 21 días la lesión temprana evoluciona a lesión establecida, la cual mostrará un mayor edema y es posible considerarla como una gingivitis "establecida"(4).

El propósito de este estudio es lograr identificar si existe o no una relación directa entre los microorganismos que habitan en el medio supragingival y subgingival o si son independientes unos de otros. De ser ésta una relación de dependencia directa, en donde sea necesaria la presencia de la placa bacteriana supragingival para el normal desarrollo de los microorganismos subgingivales, sugeriría una posible disminución de la virulencia por un fenómeno de reducción del número de bacterias del saco periodontal o por alteraciones en el metabolismo normal de la microbiota subgingival en ausencia de la placa bacteriana supragingival $\mathrm{y}$, por consiguiente, una disminución en la progresión de la patología periodontal.

\section{MATERIALES Y MÉTODOS}

\section{Selección de pacientes}

Para conformar el grupo estudio, se examinaron entre los meses de agosto y noviembre del año 2008 en la clínica de diagnóstico de la Universidad de Chile un total de 40 individuos, de los cuales 7 cumplieron con los criterios de inclusión.

La selección de los pacientes con periodontitis crónica se realizó de acuerdo a los siguientes criterios de inclusión:

- Individuos mayores de 30 años, todos ellos con al menos 14 dientes sin contabilizar los terceros molares de los cuales al menos 6 debían ser molares. Presentar al menos 4 sacos periodontales de profundidad de sondaje mayor o igual a $5 \mathrm{~mm}$ y 6 sitios con pérdida de inserción clínica mayor o igual a $3 \mathrm{~mm}$.

Por otra parte los criterios de exclusión comprendieron:

- Haber recibido algún tipo de terapia periodontal previamente, condiciones médicas que requirieran premedicación con antibióticos, administración de medicamentos tales como antibióticos 3 meses antes del comienzo del estudio y antinflamatorios esteroidales y no esteroidales 6 meses antes del comienzo del estudio, embarazo o tener afecciones sistémicas que pudieran afectar el desarrollo de la enfermedad periodontal.

No fue considerado el hábito tabáquico en los criterios de selección de la muestra, debido a que este trabajo es un modelo piloto de un número reducido de pacientes, sumado a que sólo contempla el análisis microbiológico por lo que no se estudiaron los cambios clínicos en esta primera etapa.

Todos los individuos que ingresaron en este estudio firmaron un consentimiento informado previo al inicio de éste. Terminado el estudio todos los individuos participantes ingresaron a un programa de tratamiento y mantención de la enfermedad periodontal.

\section{Evaluación clínica}

Se realizó el diagnóstico de enfermedad periodontal crónica moderada y severa de acuerdo a los parámetros diagnósticos de profundidad de sondaje y pérdida de inserción clínica. Además, para el diagnóstico se efectuó una anamnesis al paciente, la cual quedo registrada en una ficha clínica que incluía los criterios de inclusión y exclusión.

Se efectuó una medición dicotómica respecto a la presencia de placa bacteriana supragingival, considerándose cuatro sitios por diente (mesial, distal, lingual, vestibular).

Se realizaron mediciones replicadas de la profundidad de los sacos periodontales y del nivel de inserción clínica y una medición dicotómica respecto de la presencia de sangramiento al sondaje en seis sitios por diente (mesiobucal, bucal, distobucal, distolingual, lingual, mesiolingual). Estas mediciones fueron realizadas con una sonda periodontal milimetrada, tipo Carolina del Norte (Hufriedy).

Posterior al sondaje se seleccionó por cada paciente el sitio periodontal afectado con mayor profundidad al sondaje de cada cuadrante de la boca, siendo estos los sitios empleados para la toma de muestra microbiológica subgingival.

\section{Remoción de la placa bacteriana supragingival}

La remoción de la placa bacteriana supragingival se realizó con ultrasonido Cavitron Bobcat Pro Dentsply, $25 \mathrm{Khz}$ de potencia (25.000 ciclos por segundo) con inserto FSI $10 \mathrm{Hu}$ - friedy el día 0. La potencia y el agua empleada en todos los individuos fue media.

\section{Toma de muestra placa bacteriana subgingival}

Una vez realizado el destartraje supragingival a la boca completa se identificó el sitio más profundo de cada cuadrante, se secó y aisló en forma relativa con gasa estéril. Una vez seco y aislado se introdujeron en el saco periodontal dos conos de papel estéril $\left(n^{\circ} 35\right)$ hasta la profundidad del saco manteniéndose por 20 segundos.

Una vez retirado del saco periodontal, el cono de papel se colocó inmediatamente en $1 \mathrm{ml}$ de medio de transporte (RTF).

\section{Cultivo microbiológico de las muestras de placa subgingingival}

A partir de la muestra se tomaron 100ul con una micropipeta graduada y se efectuaron diluciones seriadas en un medio de buffer fosfato de sodio.

Fueron sembrados $100 u$ de la dilución $10^{-2}$ y $10^{-3}$ en placas con agar sangre hemina menadiona. Las placas se cultivaron a $36^{\circ} \mathrm{C}$ en condiciones de anaerobiosis estricta por un periodo de 14 días.

Una vez transcurridos los 14 días se procedió a realizar el diagnóstico diferencial de Porphyromona gingivalis y Prevotella intermedia, mediante el aspecto de las colonias bajo lupa estereoscópica y la prueba de fluorescencia en metanol.

Cuantificación de Unidades Formadoras de Colonia (UFC) y Porphyromonas gingivalis $(\mathrm{Pg})$.

La cuantificación de bacterias se realizó mediante la observación del número de colonias encontradas en las placas de agar bajo lupa estereoscópica y a partir de esta medida se determinó la microbiota total cultivable expresándolo como unidades formadoras de colonias (UFC) por ml de medio de transporte (RTF).

A partir de este análisis y mediante un cálculo aritmético (Figura 1) se determinó el porcentaje de Porphyromonas gingivalis del total de la muestra.

$\frac{\text { UFC total de la muestra }}{100 \%}=\frac{\text { UFC }}{\mathrm{X} \%}$

Figura 1. Fórmula aritmética empleada para calcular el porcentaje de Pg presente en la placa cultivada de la muestra de bacterias del saco periodontal. Donde se indica $\mathrm{X} \%$ como porcentaje de Pg con respecto al porcentaje de UFC total de la muestra.

\section{Análisis de datos}

Los datos obtenidos de la cuantificación de la microbiota total cultivable y de los porcentajes de $\mathrm{Pg}$ fueron analizados mediante un 
software estadístico Stata versión 8.0. Utilizándose el Test-t pareado para analizar los parámetros de comparación de los resultados de la cuantificación de Unidades Formadoras de Colonia (UFC), ya que la distribución de la muestra en este caso fue normal. Al contrario de lo observado en los resultados obtenidos de los porcentajes de $\mathrm{Pg}$ en donde la distribución de la muestra no fue normal por lo que se empleó el test Wilcoxon para analizar estadísticamente los parámetros de comparación.

\section{RESULTADOS}

Como se puede observar en la Tabla 1 la totalidad de los individuos participantes quedó conformada por un $42,8 \%$ de mujeres y un $57,2 \%$ por hombres ( 3 mujeres y 4 hombres), quienes tenían un rango etario entre los 38 y 68 años (con un promedio de 52,14 $\pm 9,47$ años de edad).

Los individuos con diagnóstico de periodontitis crónica generalizada severa resultaron ser un $71,4 \%$, mientras que un $28,57 \%$ presentó un diagnóstico de periodontitis crónica generalizada moderada.

En la Tabla 1, además, se pueden apreciar los promedios y la desviación estándar de la profundidad de sondaje, el nivel de inserción clínica, la presencia de placa y el sangramiento al sondaje de los individuos participantes del estudio. El promedio de la profundidad de sondaje y el nivel de inserción clínica de los individuos participantes fue de 5,15 $\pm 2,33 \mathrm{~mm}$ y $5,64 \pm 2,90 \mathrm{~mm}$ respectivamente (Tabla 1). Mientras, que el porcentaje promedio de los sitios con sangramiento al sondaje y la presencia de placa bacteriana fueron de $51,75 \pm 29,53$ y $76,67 \pm 17,25$ (Tabla 1 ).

Tabla 1. Características clínicas de los individuos (promedio desviación _estándar).

\begin{tabular}{|c|c|}
\hline \multicolumn{2}{|c|}{ Características clínicas de los individuos estudiados ( $n=7$ ) } \\
\hline Periodontitis crónica generalizada severa (\%) & 71,4 \\
\hline Periodontitis crónica generalizada moderada (\%) & 28,57 \\
\hline Edad (años) & $52,14_{-9}^{+} 9,47$ \\
\hline Mujeres (\%) & 42,85 \\
\hline Profundidad de sondaje $(\mathrm{mm})$ & $5,15_{-}^{+} 2,33$ \\
\hline Nivel de inserción clínico (mm) & $5,64_{-}^{+} 2,90$ \\
\hline Sangramiento al sondaje (\%) & $51,75_{-}^{+} 29,53$ \\
\hline Presencia de placa $(\%)$ & $76,67+17,25$ \\
\hline
\end{tabular}

Cuantificación de Unidades Formadoras de Colonia (UFC)

En la Tabla 2 se pueden observar los promedios y la desviación estándar de la cuantificación de la microbiota total cultivable de los individuos participantes $(n=5)$, en donde se identifican los diferentes tiempos en que fueron tomadas las muestras que corresponden a la muestra basal tomada el día 0 , es decir, previo a la remoción de la placa bacteriana supragingival con ultrasonido por parte del operador al día, a los 7 y 21 días de eliminada la placa bacteriana supragingival.

Las muestras básales de los individuos $\mathrm{P} 1$ y $\mathrm{P} 2$ no obtuvieron crecimiento bacteriano a los 14 días de sembradas y cultivadas en estricta anaerobiosis, la causa se desconoce, por lo que para efecto de análisis estadístico estos sujetos debieron ser eliminados del estudio reduciendo el $\mathrm{n}$ de 7 a 5 individuos. Sin embargo, las muestras controles sí fueron consideradas para formular las conclusiones y la discusión del trabajo.

Por otra parte es posible observar que existe una disminución en las UFC de las muestras tomadas los días posteriores al destartraje supragingival, siendo notablemente menor la cantidad de UFC a las 24 horas de eliminada la placa supragingival en comparación con la muestra basal de todos los individuos (Figura 2). En este caso se muestra una tendencia a la disminución, aunque sólo se vio bordeando la significancia estadística $(p=0,053)$ al comparar la muestra basal con los 21 días de realizada la remoción de placa bacteriana supragingival.

En la Figura 3 se puede observar el descenso importante de los porcentajes de $\mathrm{Pg}$, viéndose mucho más marcado este fenómeno al día de realizado el destartraje supragingival. La disminución del porcentaje de Pg continuó de forma más lineal en los controles posteriores (7 y 21 días). Una disminución estadísticamente significativa ( $p$ menor a 0,05 ) pudo observarse al comparar la muestra basal con la tomada a los 7 y 21 días de realizada la remoción de la placa supragingival.
Tabla 2. Media y desviación estándar de la microbiota total cultivable subgingival expresada en UFC/ml de sacos periodontales de individuos con periodontitis crónica moderada y severa antes del destartraje supragingival (muestra basal), a las 24 horas, a los 7 y 21 días de realizada la profilaxis supragingival. La misma información se expresa para Pg.

\begin{tabular}{|c|c|c|c|}
\hline \hline Variable & $\mathbf{n}$ & Media & Desv. Est. \\
\hline Basal & 5 & $3.46 \mathrm{e}+07$ & $3.35 \mathrm{e}+07$ \\
\hline Horas & 5 & $1.56 \mathrm{e}+07$ & $1.61 \mathrm{e}+07$ \\
\hline Días & 5 & $1.20 \mathrm{e}+07$ & $1.13 \mathrm{e}+07$ \\
\hline $\mathrm{Pg}$ & 5 & 31.452 & 27.2349 \\
\hline
\end{tabular}

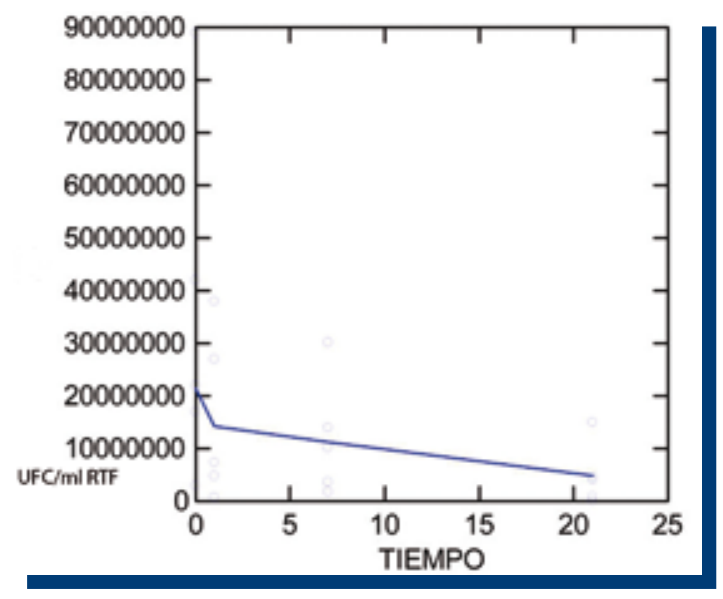

Figura 2. Gráfico en donde se observa la disminución de la cantidad de UFC posterior al destartraje supragingival. Es posible observar que a las 24 horas la disminución de UFC es marcada, posterior a eso la disminución de UFC se vuelve constante en el tiempo hasta llegar a la mayor disminución a los 21 días de realizada la profilaxis.

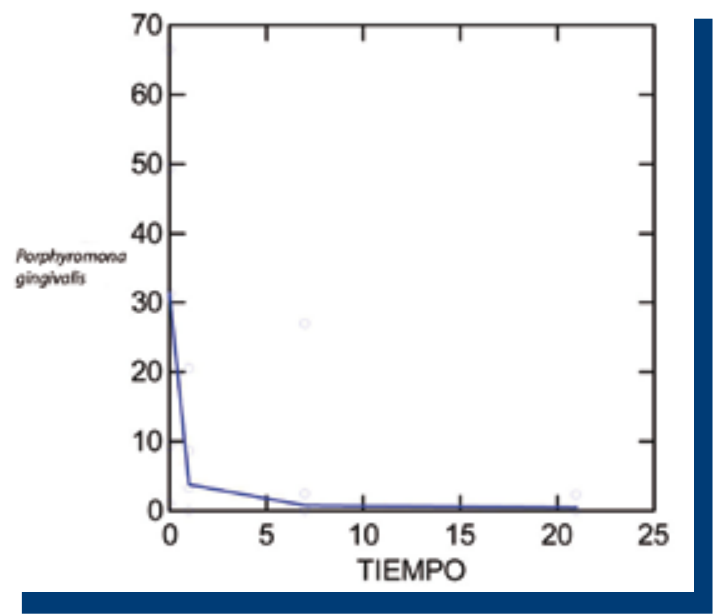

Figura 3. Gráfico en donde se expresa la disminución del porcentajes de Pg presente en la microbiota subgingival posterior al destartraje supragingival. Se aprecia que a las 24 horas la disminución del porcentaje de Pg es muy marcado, luego sigue disminuyendo pero de manera más constante con respecto a la primera medición hasta llegar a los menores porcentajes a los 21 días de realizado el destartraje supragingival. 


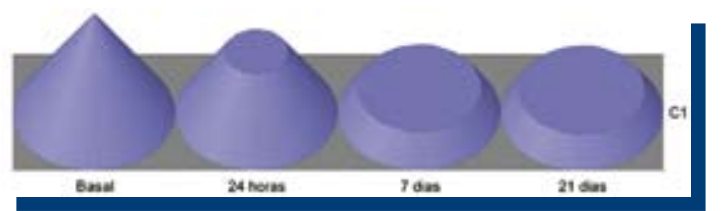

Figura 4. Esquema que grafica la disminución de la cantidad de microorganismos en las tomas de muestra posterior al destartraje supragingival (24 horas, 7 y 21 días).

\section{Identificación y cuantificación de Pg}

Tal como se puede observar en la tabla 2 , al realizar la identificación mediante la fisonomía bacteriana y la prueba de inmunofluoresencia se pudo determinar del total de la microbiota cultivable el porcentaje correspondiente a Porphyromona gingivalis. Los porcentajes fueron identificados en la muestra basal (antes del destartraje supragingival), a las 24 horas, a los 7 y 21 días de eliminada la placa bacteriana supragingival. Observándose una disminución en la proporción de $\mathrm{Pg}$ posterior a la remoción de placa supragingival mediante ultrasonido, en comparación con la muestra basal de los individuos que presentaron presencia de $P g$ en su microbiota bacteriana (Figura 3). Las muestras básales de los individuos P1 y P2 no obtuvieron crecimiento bacteriano a los 14 días de sembradas y cultivadas en estricta anaerobiosis, siendo la causa desconocida, por lo cual no se pudo identificar la presencia de $P g$.

$\mathrm{P} 1$ no presentó crecimiento bacteriano de $P g$ en ninguna de las muestras registradas. Los porcentajes de los individuos P2, P4, P6 y P7 presentaron una disminución constante de estos microorganismos, mientras que P3 y P5 presentaron un crecimiento bacteriano de $\mathrm{Pg}$ a los 7 y 21 días respectivamente, sin embargo los porcentajes de $P g$ fueron notablemente menores a los identificados en la muestra basal. La disminución de los porcentajes de $P g$ llegó a reducirse a $0 \%$ a los 21 días del destartraje supragingival en los pacientes P3, P4, P6 y P7 (Figura 2). En los individuos $P 5$ y $P 7$ el porcentaje de $P g$ se redujo de $9,3 \%$ y $31,3 \%$ respectivamente a $0 \%$ a las 24 horas de realizado el destartraje supragingival, sin embargo en P5 existió un aumento del porcentaje de $P g$ a los 21 días de realizada la remoción de placa supragingival en un $2,3 \%$.

Los porcentajes de $P g$ obtenidos en las diferentes muestras de placa bacteriana subgingival de todos los individuos del estudio fueron analizados utilizando la prueba estadísticas de test Wilcoxon, obteniéndose que las diferencias estadísticamente significativas se podían observar al comparar la muestra basal con la muestra control a los 7 y 21 días de removida la placa supragingival.

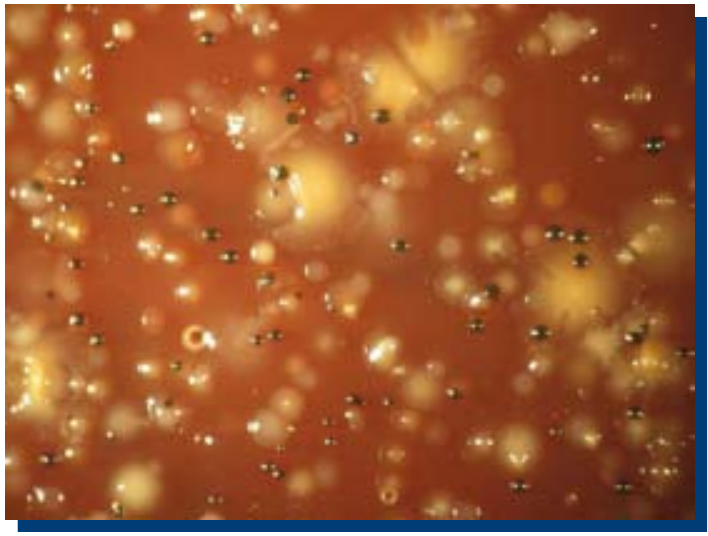

Figura 5. Muestra basal subgingival del paciente $\mathrm{n}^{0} 7$ con diagnóstico de periodontitis crónica generalizada severa. Se logra apreciar la gran cantidad de colonias de microorganismos del medio subgingival, específicamente la concentración de colonias de microorganismos pigmentados de negro los que fueron identificados como Pg.

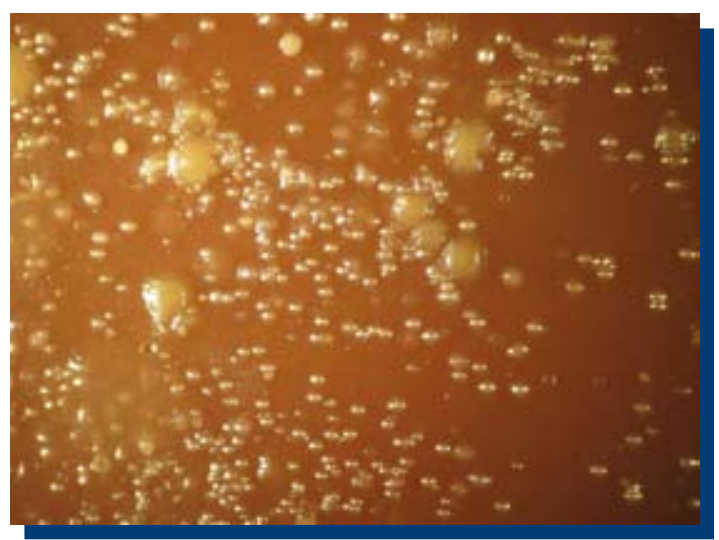

Figura 6. Muestra control de la microbiota subgingival a las 24 horas de realizado el destartraje supragingival. Se logra apreciar una disminución en el total de colonias y la ausencia de colonias de microorganismos pigmentados de negro.

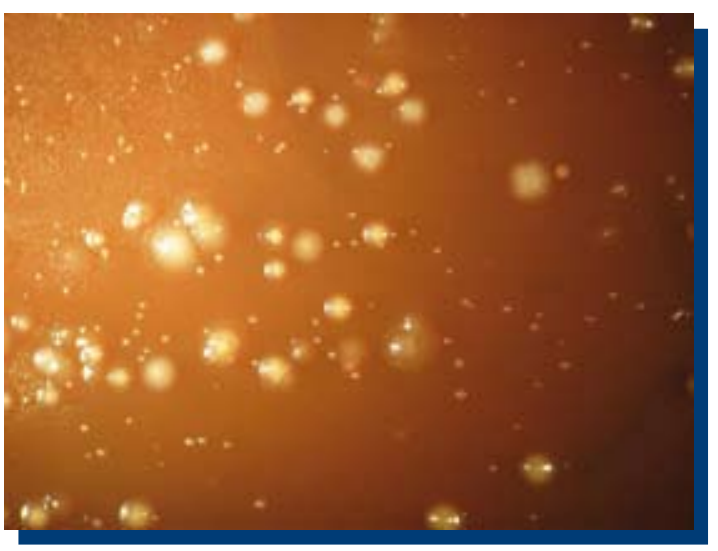

Figura 7. Muestra control de la microbiota subgingival los 7 días de removida la placa bacteriana supragingival. Aquí se logra identificar la marcada disminución del total de las colonias de microorganismos con respecto a las mediciones iniciales (basal) y al primer control (24 horas).

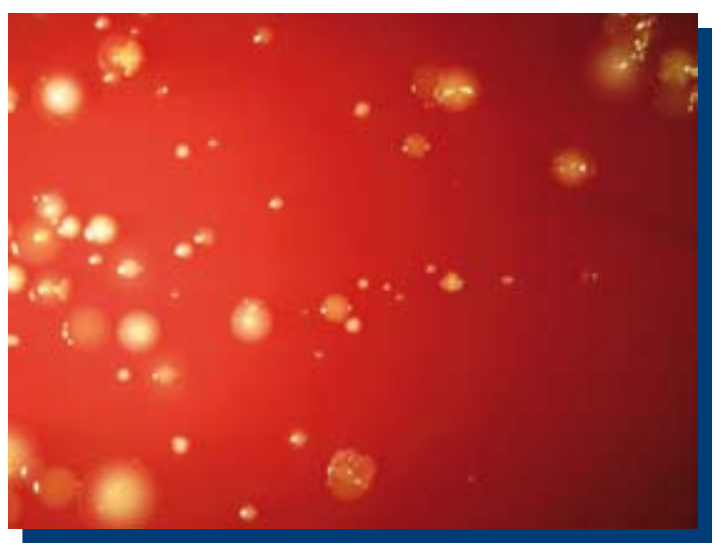

Figura 8. Muestra control de la microbiota subgingival final a los 21 días de removida la placa bacteriana supragingival. Se logra observar la mayor disminución de colonias de microorganismos subgingivales con respecto a la toma basal y a los controles anteriores (24 horas y 7 días).

\section{DISCUSIÓN}

La Periodontitis crónica corresponde a un fenómeno inflamatorio inducido por bacterias que afectan a las estructuras de soporte de los dientes, la cual conduce a la destrucción de ligamento periodontal y hueso alveolar ${ }^{(1)}$.

Estas bacterias forman parte de la placa, la cual puede variar como consecuencia de interacciones bacterianas o en respuesta a cambios del ambiente. Se ha sugerido que la placa supragingival puede 
afectar la composición de la placa subgingival, ya que provee a ésta de sustancias nutritivas, manteniendo el ambiente anaerobio del saco periodontal y facilitando la adherencia de otros microorganismos. Por lo tanto, el retiro de la placa supragingival teóricamente podría afectar la composición de la placa subgingival y posiblemente la condición periodontal ${ }^{(2)}$

El presente trabajo demuestra que existe una tendencia a la disminución en la cantidad de la microbiota total cultivable subgingival posterior a la remoción de la placa bacteriana supragingival realizada por el profesional. Los resultados indican que a los 21 días de realizada la profilaxis supragingival se observa la mayor disminución de unidades formadoras de colonias (UFC) al ser comparada con la muestra basal. Sin embargo, en este caso el p valué es de 0,053 , lo que indica que está bordeando la significancia estadística. Mientras que los resultados observados en los porcentajes de Porphyromona gingivalis $(\mathrm{Pg})$ indican una marcada tendencia a la disminución en todos los controles posteriores a la remoción de la placa supragingival. No obstante, la disminución estadísticamente significativa de los porcentajes de $\mathrm{Pg}$ se hace presente al comparar la toma basal con los días 7 y 21 de removida la placa supragingival.

Aunque las metodologías empleadas tanto para la eliminación de placa supragingival y los tiempos en que fueron tomadas las muestras control varían entre los distintos estudios, en la mayoría de los resultados es posible observar que existen variaciones en la microbiota subgingival al remover la placa bacteriana supragingival. Estas variaciones pueden comprender en cantidad o en el cambio de los microorganismos encontrados en el medio subgingival.

Ya en 1985 Pearlin Kho y cols estudiaron el efecto del control de la placa supragingival sobre la microbiota subgingival. Mediante el destartraje supragingival con ultrasonido e instrucción de higiene oral por parte del operador. En las evaluaciones microbiológicas mediante microscopio de campo oscuro se logró realizar la comparación entre la muestra basal (antes de la profilaxis) y a los 7, 21 y 49 días de removida la placa supragingival, encontrando además una reducción en las unidades formadoras de colonias (UFC) y específicamente en el número de bacteroides pigmentados y de Capnocitophaga ${ }^{(2)}$.

En la misma línea de investigación Loss B. Claffey N. y Crigger M. (1988) analizaron los efectos de los cuidados de higiene oral medidos bajo parámetros clínicos y microbiológicos sobre la enfermedad periodontal. Esto se realizó en pacientes con diagnóstico de periodontitis crónica severa. Las muestras microbiológicas fueron tomadas el día 0 (basal), a las 6 y 12 semanas. La metodología en este estudio contempló la enseñanza de técnicas de higiene el día 0 y a las 6 semanas, lo cual fue complementado con el destartraje supragingival y subgingival en la semana 12. Los resultados indicaron que no existieron cambios significativos en la microbiota subgingival en la muestra basal y a las 6 semanas. Por el contrario, sí se observó una reducción significativa bajo todos los parámetros microbiológicos a la semana de eliminada la placa bacteriana supragingival.

Algo similar fue registrado por Dahlén G. Lindhe J. y cols (1992) quienes estudiaron los efectos del control de placa supragingival en la microbiota subgingival de pacientes con periodontitis crónica moderada. En este estudio fueron analizados 300 sujetos, los cuales ingresaron a un programa que consistía en un control de placa en base a una meticulosa instrucción de higiene oral, destartraje supragingival profesional y un periodo de seguimiento de 2 años. Los resultados de este estudio llevaron a concluir que al realizar un cuidadoso control de placa supragingival bajo este protocolo, cambia la cantidad y la composición de la microbiota subgingival(3).

Nuestros resultados, por lo tanto, concuerdan con la gran mayoría de los obtenidos por otros investigadores, en cuanto a que existe una tendencia a la disminución de la microbiota total cultivable subgingival y de ciertos microorganismos específicos, como es el caso particular de nuestro estudio de Porphyromona gingivalis $(\mathrm{Pg})$ al eliminar la placa bacteriana supragingival.

Mc Nabb H, Mombelli A y NP Lang (1992), analizaron los efectos microbiológicos que se producían en sacos periodontales moderadamente profundos $(4$ a $5 \mathrm{~mm})$ al realizar una profilaxis supragingival 3 veces por semana. 6 sujetos ingresaron a este estudio, los cuales presentaban una pobre higiene oral, con un diagnóstico de gingivitis severa. La metodología utilizada dividió en 3 fases la investigación; una primera fase en donde fue empleado el diseño de Split Mouth, realizándose el destartraje supragingival al cuadrante superior e inferior derecho tres veces por semana por un periodo de 12 semanas. Una vez terminada esta primera etapa se proseguía a realizar una segunda fase en donde se aplicaban los mismos protocolos empleados en la fase 1, pero esta vez en los cuadrantes superior e inferior del lado izquierdo. Durante el periodo experimental, los sujetos no recibieron instrucción de higiene oral. Las observaciones microbiológicas mostraron que existe una gran disminución en las proporciones de Porphyromona gingivalis $(P g)$ y un aumento de las formas cocáceas en ambas fases en las muestras tomadas posterior al destartraje supragingival comparadas con la muestra basal. Las diferencias estadísticamente significativas se observan a partir de las 9 semanas posterior a la remoción de la placa supragingival.

Los resultados de Mc Nabb y cols generan como interrogante, si el tiempo desde la toma de muestra basal y el último control podría ser estadísticamente relevante. En nuestro trabajo, la disminución de microbiota total cultivable y específicamente de Porphyromona gingivalis posterior al destartraje supragingival disminuye más a medida que pasa el tiempo, encontrando los valores más bajos en el último control, lo que corresponde a los 21 días de eliminada la placa supragingival siendo en este día estadísticamente significativa la diferencia. Lo que nos orienta a que quizás para próximas investigaciones en el tema sería interesante considerar la variable tiempo, distanciando lo que más se pueda la medición basal con respecto a la muestra control final.

Nuestros resultados muestran que la cantidad de microorganismos subgingivales disminuye al igual que los porcentajes de $P g$ posterior a la remoción de placa supragingival. Estos resultados coinciden con lo observado por Helström M-k y cols (1996) en donde a 12 sujetos que presentaban enfermedad periodontal moderada a severa, se les realizó profilaxis supragingival 2 a 3 veces por semana por un periodo de 30 semanas complementado con técnicas de higiene oral (Técnica de Bass). En esta investigación las muestras fueron tomadas el día basal y a las 30 semanas posterior al tratamiento, los resultados indicaron que al recibir estos sujetos frecuentemente la eliminación profesional de la placa supragingival, combinada con un cuidadoso autocontrol de placa se puede observar un efecto marcado sobre la microbiota subgingival en sacos periodontales moderados y profundos, en donde se puede identificar una reducción en el número total de los microorganismos cultivados, as como el porcentaje de sitios con Porphyromona gingivalis ${ }^{(4)}$

Trabajos más recientes como el de Ximénez-Fyvie LA, Haffajee AD y cols (2000) también confirman nuestra hipótesis de que si existe una disminución en la microbiota total cultivable subgingival al remover la placa supragingival. Estos autores determinaron el efecto que produce la profilaxis administrada profesionalmente para el retiro de la placa supragingival sobre la composición de la microbiota supragingival y subgingival. 18 sujetos adultos con diagnóstico inicial de periodontitis, los cuales ya habían sido tratados y se encontraban en una fase de mantenimiento de terapia fueron analizados clínicamente y microbiológicamente en este estudio, mediante una toma de muestra basal, a los 3,6 y 12 meses posterior al destartraje supragingival profesional. Después de la primera visita del paciente (basal), a los sujetos se les realizó el debridamiento y pulido radicular de ser esto necesario y luego se planificó el retiro de placa profesional supragingival semanalmente durante 3 meses. Los resultados indicaron que existió una considerable reducción en 22 de las 40 especies de las muestra supragingival, mientras que también se redujo notoriamente 34 de 40 especie en las muestras de placa subgingival. Sin embargo en las muestras de placa supragingival, fue menor el efecto observado para el género Actinomyces, en particular a los 3 y 6 meses $^{(5)}$.

A partir de todo lo anteriormente señalado es posible inferir que los resultados obtenidos en nuestro trabajo se encuentran dentro de los parámetros que indica la literatura, sin embargo falta investigar aún más y definir un protocolo único de remoción de placa supragingival, ya que las variables para esperar un mismo resultado aumentan y hace más complejo el análisis comparativo entre las diferentes investigaciones.

Por otra parte, si bien los hallazgos de este estudio indican que existe una marcada tendencia a la disminución de microorganismos subgingivales al remover la placa bacteriana supragingival, existen autores que contradicen estos resultados. Tal es el caso de Beltrami M y cols (1987) quienes estudiaron a 8 sujetos con diagnóstico de periodontitis crónica moderada a severa, y que fueron sometidos a una remoción de placa bacteriana supragingival profesional 3 veces por semana por un periodo de 3 semanas. El grupo control correspondía a los sitios contralaterales de los sitios estudiados. Los resultados microbiológicos encontrados por estos autores señalan que no existió una variación estadísticamente significativa en ningún grupo (sitos tratados $\mathrm{v} / \mathrm{s}$ contralateral no tratado). Los investigadores concluyen que una vez formada la placa subgingival en el saco periodontal, ésta constituiría un ecosistema independiente con respecto a la placa supragingival( ${ }^{(6)}$.

Una de las limitaciones del presente estudio fue la reducida muestra $(n)$ debido en parte a los criterios de inclusión y exclusión y al corto periodo de investigación, lo que impidió la captación de más sujetos con similares características. Al ser el " $n$ " pequeño las pruebas estadísticas empleadas posiblemente no muestren el real escenario que se produce al eliminar la placa bacteriana supragingival, en donde existe una tendencia directa a la disminución tanto de UFC como a los porcentajes de $\mathrm{Pg}$, lo que se observa concretamente en los gráficos registrados. 
Complementariamente del total de individuos que formaron parte de este estudio ${ }^{(7)}$ en dos de ellos no existió desarrollo microbiano a los 14 días de sembradas las muestras, las cuales correspondían a la muestra basal. Hasta ahora no se ha logrado esclarecer la causa aparente. Al no desarrollarse la muestra basal, estos sujetos no fueron considerados para el análisis estadístico reduciéndose aún más el tamaño de la muestra $(n=5)$.
Este trabajo apunta servir como referencia para posteriores investigaciones que incluyan un mayor número de individuo y protocolos de eliminación de placa bacteriana supragingival más estandarizados dando una mayor validez externa a la metodología de trabajo.

\section{REFERENCIAS BIBLIOGRÁFICAS}

1. Johnson TC. Reinhardt RA. Payrte JB. Dyer JK. Patil KD. Experimental Gingivitis in Periodontitis-Susceptible Subjects. J Clin Periodomol 1997: 24: 618-625.

2. Pearlin Kho, Frederick C. Smales and Jeremy M. Hardie. The Effect of Supragingival Plaque Control on the Subgingival Microflora. J Clin Periodontol 1985. 12: 676-686.

3. Dahlén G, Lindhe J, Sato K, Hanamura H and Okamoto H. The Effect of Supragingival Plaque Control on the Subgingival Microbiota in subjects with periodontal disease. J Clin Periodontol1992. 19: 802-809.
4. Hellström M-K, Ramberg P, Krok L, Lindhe J. The Effect of Supragingival Plaque Control on the Subgingival Microflora in human Periodontitis. J Clin Periodontol 1996. 23: 934-940.

5. Ximénez-Fyvie LA, Haffajee AD, Som S, Thompson M, Torresyap G, SocranskySS. The Effect of Repeated Professional Supragingival Plaque Removal on the Composition of the Supra- and Subgingival Microbiota. J Clin Periodontol 2000; 27: 637-647.

6. Beltrami M, Bickel M and Baehni PC. The Effect of Supragingival Plaque Control on the Composition of the Subgingival Microflora in Human Periodontitis. J Clin Periodontol. 1987. 14: 161-164. 